\title{
Fontes Nitrogenadas e Uso de Sacharomyces cerevisiae em Dietas à Base de Cana-de-Açúcar para Novilhos: Consumo, Digestibilidade, Balanço Nitrogenado e Parâmetros Ruminais
}

\author{
Elzânia Sales Pereira1, Augusto César de Queiroz ${ }^{2}$, Mario Fonseca Paulino², Paulo Roberto Cecon ${ }^{3}$, \\ Sebastião de Campos Valadares Filho ${ }^{2}$, Lidia Ferreira Miranda ${ }^{5}$, Alex Martins Varela de Arruda ${ }^{1}$, \\ Alberto Magno Fernandes ${ }^{4}$, Luciano da Silva Cabral ${ }^{4}$
}

\begin{abstract}
RESUMO - O objetivo do presente estudo foi avaliar os efeitos das fontes nitrogenadas e o uso de Sacharomyces cerevisiae em dietas à base de cana-de-açúcar sobre os consumos e as digestibilidades aparentes totais e parciais de matéria seca (MS), matéria orgânica (MO), proteína bruta (PB), extrato etéreo (EE), carboidratos totais (CHO), fibra em detergente neutro (FDN) e carboidratos nãoestruturais (CNE), o balanço nitrogenado e os parâmetros ruminais. Foram utilizados quatro novilhos Holandês-Zebu, fistulados no rúmen e abomaso, alimentados com quatro rações à base de cana-de-açúcar, constituídas de duas fontes nitrogenadas (uréia ou cama de frango) combinadas com dois níveis de Sacharomyces cerevisiae (0 e 10 g/dia). Utilizou-se delineamento em quadrado latino 4 x 4. A fibra em detergente neutro indigestível (FDNi) foi utilizada como indicador, para determinar as digestibilidades aparentes totais e parciais. Os consumos de MS, MO, EE, CT e CNE não foram influenciados pelas fontes nitrogenadas e pela utilização de Sacharomyces cerevisiae. Os consumos de PB e FDN foram maiores para as dietas suplementadas com cama de frango. Os coeficientes de digestibilidades totais de PB e EE foram maiores para as dietas constituídas de uréia. As digestibilidades aparentes totais de MS, MO, CT e FDN não foram influenciadas pelas fontes nitrogenadas e pela utilização de Sacharomyces cerevisiae. O pH do líquido ruminal decresceu linearmente para as dietas suplementadas com uréia e apresentou comportamento quadrático, quando estas dietas foram combinadas com Sacharomyces cerevisiae. As concentrações de amônia no líquido ruminal apresentaram comportamento quadrático, estimando-se valores máximos de 16,90;26,12;18,48; e 14,40 mg/100 mL para os tratamentos constituídos de cana-deaçúcar e uréia; cana-de-açúcar, uréia e Sacharomyces cerevisiae; cana-de-açúcar e cama de frango; e cana-de-açúcar, cama de frango e Sacharomyces cerevisiae, respectivamente.
\end{abstract}

Palavras-chave: bovinos, consumo, digestibilidade, suplementos microbianos dietéticos

\section{Sources of Non-Protein Nitrogen and the Addition of Sacharomyces cerevisiae to Sugar Cane Based Diets for Young Bulls: Intake, Digestibility, Nitrogen Balances and Ruminal Parameters}

\begin{abstract}
The objective of the present study was to evaluate the effects of the non-nitrogenous sources and the addition of Sacharomyces cerevisiae to sugarcane based diets on the intakes and the total and partial apparent digestibilities of dry matter (DM), organic matter $(\mathrm{OM})$, crude protein $(\mathrm{CP})$, ether extract (EE), total carbohydrates (TC), neutral detergent fiber (NDF) and non- structural carbohydrates (NEC). The nitrogen balance and ruminal parameters were also evaluated. Four Holstein-Zebu young bulls rumen and abomasal fistulated were allotted to a $4 \times 4$ Latin Square design in a 2 x 2 factorial arrangement. The animals were fed with sugar cane based diets, supplemented with two nitrogenous sources (urea or poultry litter) and two daily Sacharomyces cerevisiae addition ( 0 and $10 \mathrm{~g} / \mathrm{anim}$.). The indigestible neutral detergent fiber (NDFi) was used as a marker, to determine the total and partial apparent digestibilities of the nutrients. The intakes of DM, OM, EE, TC, NEC was not influenced by the nitrogenous sources and by the Sacharomyces cerevisiae addiction. The intakes of CP and NDF were higher for the diets supplemented by poultry litter. The coefficients of total digestibilities of CP and EE were higher for diets with urea. The apparent total digestibilities of DM, OM,TC, and NDF were not influenced by the nitrogenous sources and by the Sacharomyces cerevisiae addiction. The ruminal $\mathrm{pH}$ linearly decreased for the diets supplemented with urea, and presented a quadratic response when these diets were combined with Sacharomyces cerevisiae. The ruminal ammonia concentrations presented a quadratic behavior, and the maximum estimated values of $16.90 ; 26.12 ; 18.48$ and $14.40 \mathrm{mg} / \mathrm{dL}$ for the diets with sugar-cane and urea, sugar cane, urea and Sacharomyces cerevisiae; sugar cane and poultry litter; sugar cane, poultry litter and Sacharomyces cerevisiae, respectively.
\end{abstract}

Key Words: cattle, dietetic microbes supplements, digestibility, intake

\footnotetext{
${ }_{1}^{1}$ Professor do Departamento de Zootecnia - UNIOESTE - PR. E.mail: elzania@unioeste.br

2 Professor do Departamento de Zootecnia da UFV - MG. Bolsista CNPq.

${ }^{3}$ Professor do Departamento de Estatística da UFV - MG.

${ }^{4}$ Estudante de Doutorado do Departamento de Zootecnia da UFV - MG.

5 Estudante de Doutorado do Departamento de Medicina Veterinária e Zootecnia da UFMG - MG.
} 


\section{Introdução}

O controle do consumo envolve estímulos de fome e saciedade, que operam por intermédio de vários mecanismos neurohumorais. Os mecanismos homeostáticos que regulam o consumo procuram assegurar a manutenção do peso corporal e as reservas teciduais durante a vida adulta. Os mecanismos homeorréticos ajustam o consumo para atender as exigências específicas de vários estádios fisiológicos, como crescimento, prenhês e lactação. $\mathrm{O}$ apetite ou impulso de alimentação é função dos requerimentos energéticos, determinados pelo potencial genético ou pela condição fisiológica (MERTENS, 1994).

O consumo voluntário é empregado para designar o limite máximo do apetite (THIAGO e GILL, 1990), sob condições de alimentação ad libitum, e constitui-se em importante critério na formulação de dietas para bovinos leiteiros e gado de corte, no cálculo da área necessária de pastagens em sistemas extensivos e semi-intensivos, para o estabelecimento de culturas de milho e sorgo para a ensilagem, bem como para o controle de estoques de alimentos. Isto significa que o grau de exatidão de suas estimativas possui importância capital (NATIONAL RESEARCH COUNCIL - NRC, 1989; MERTENS, 1992).

Definida sua importância, pode-se então justificar a existência e o contínuo surgimento de numerosos estudos que objetivaram comprovar hipóteses a respeito dos mecanismos de regulação do consumo voluntário.

O consumo voluntário, como tem sido proposto, pode ser regulado por três mecanismos: o psicogênico, que envolve comportamento do animal face aos fatores inibidores ou estimuladores relacionados ao alimento ou ao ambiente; o fisiológico, em que a regulação é dada pelo balanço nutricional; e o físico, relacionado com a capacidade do animal de distensão do rúmen (MERTENS, 1994). Por esta razão, tamanho e condição corporal, raça, estágio fisiológico e as características da dieta são fatores universalmente aceitos como determinantes do consumo voluntário.

A fibra em detergente neutro (FDN) é uma entidade dietética bastante representativa do volume ocupado pelo alimento (VAN SOEST, 1994), sendo, portanto, inversamente relacionada à densidade energética. A FDN, em dietas com elevada proporção de fração fibrosa, preenche os espaços do rúmenretículo, levando maior tempo que os conteúdos celulares para deixar este compartimento, por intermédio dos mecanismos de digestão, ruminação e passagem.
O desenvolvimento de modelos mecanicistas para a descrição, em termos quantitativos, dos processos relacionados ao trato gastrintestinal tem suporte em estudos cínéticos (MERTENS, 1993; ORSKOV e McDONALD, 1979; e VAN MILGEN et al., 1991), os quais permitiram a identificação da fração indigestível dos constituintes da parede celular vegetal, o que contribuiu consideravelmente para o estabelecimento do nível de repleção ruminal da FDN (VAN SOEST, 1994), efetivamente ocupando espaços que poderiam ser preenchidos com materiais potencialmente digestíveis, que, por sua vez, contribuíriam no atendimento à demanda energética do animal.

O processo de digestão nos ruminantes é o resultado de uma seqüência de eventos que ocorrem em diferentes segmentos do trato gastrintestinal. O local de digestão influencia a natureza dos produtos finais absorvidos, a extensão das perdas que ocorrem e, provavelmente, a resposta produtiva do animal (MERCHEN et al., 1997).

A atividade microbiana e suas funções no processo digestivo podem ser modificadas pelo $\mathrm{pH}$ ruminal. Vários estudos têm demonstrado que a adição de quantidades excessivas de concentrados à dieta dos animais resultou em redução do $\mathrm{pH}$ ruminal, devido à rápida fermentação dos carboidratos não-estruturais e à intensa produção de ácidos graxos voláteis, o que pode produzir grande impacto sobre a digestão da fibra.

A disponibilidade de carboidratos tem grande efeito sobre a utilização dos compostos nitrogenados no rúmen (RUSSELL et al., 1992). Os microrganismos utilizam peptídeos e aminoácidos para o crescimento ou fermentam aminoácidos, quando há deficiência de carboidratos, produzindo amônia. A concentração de nitrogênio amoniacal ruminal é função das taxas relativas de entrada e saída de amônia (NOLAN, 1993); a amônia entra no rúmen por diversas fontes, seja por fermentação do alimento, lise de células, proteína endógena, compostos nitrogenados solúveis diversos e excreção de protozoários. O nitrogênio amoniacal é removido do rúmen pela incorporação à matéria microbiana, por absorção pelo epitélio ruminal, ou passando para outras partes do trato digestório.

Durante muitos anos, a manipulação do ecossistema ruminal tem sido objeto de estudo por nutricionistas de ruminantes, com expectativa de melhoria da eficiência de produção destes animais.

A melhoria da utilização de volumosos de baixa qualidade pelos ruminantes pode ser obtida por meio de tratamentos físicos e químicos (MPOFU e NDLOVU, 1994), de suplementação dietética que 
atenda aos requerimentos de microrganismos fibrolíticos (LENG, 1993) e uso de aditivos microbianos que favoreçam a digestão dos componentes fibrosos dos alimentos (NEWBOLD et al., 1995). Este último aspecto tem sido objeto de interesse para maximização da degradação da parede celular. Entretanto, os resultados relatados na literatura são inconsistentes e parte desta inconsistência é atribuída à grande variação do nível de adição, espécies, dietas e tipos de aditivos microbianos (MARTIN e NISBET, 1992).

Leveduras têm sido isoladas a partir de conteúdos ruminais, embora cepas aeróbias sejam caracterizadas somente como alóctones ou transientes (ORPIN e JOBLIN, 1988). Sacharomyces cerevisiae exibe determinado grau de viabilidade ruminal. Atualmente, esta levedura tem sido utilizada em sistemas de alimentação de ruminantes (MARTIN e NISBET, 1992), promovendo melhoria no desempenho, possivelmente devido aos efeitos nos processos digestivos, na degradação da parede celular, na manutenção de níveis adequados de amônia no rúmen, na estabilização do $\mathrm{pH}$ ruminal e nos maiores rendimentos microbianos (HUHTANEN, 1991; YOON e STERN, 1995; e DOREAU E JOUANY, 1998).

O objetivo do presente estudo foi avaliar os efeitos das fontes nitrogenadas e o uso de Sacharomyces cerevisiae em dietas à base de canade-açúcar sobre os consumos e as digestibilidades aparentes totais e parciais de matéria seca (MS), matéria orgânica $(\mathrm{MO})$, proteína bruta $(\mathrm{PB})$, extrato etéreo (EE), carboidratos totais (CHO), fibra em detergente neutro (FDN) e carboidratos não-estruturais (CNE), o balanço nitrogenado e os parâmetros ruminais, utilizando-se bovinos mestiços Holandês-Zebu.

\section{Material e Métodos}

O experimento foi realizado nos Laboratórios de Animais e de Nutrição do Departamento de Zootecnia da Universidade Federal de Viçosa, localizada no município de Viçosa, Estado de Minas Gerais. A cidade de Viçosa está localizada na Zona da Mata, com altitude de $657 \mathrm{~m}$, geograficamente definida pelas coordenadas de $20^{\circ} 45^{\prime}$ de latitude sul e $42^{\circ} 51^{\prime}$ de longitude oeste, apresentando temperaturas médias anuais com máximas e mínimas de 26,1 e $14^{\circ} \mathrm{C}$, respectivamente, e precipitação pluviométrica de $1341 \mathrm{~mm}$ anuais.

Foram utilizados quatro novilhos mestiços Holandês-Zebu, com idade de 18 meses e peso médio de $300 \mathrm{~kg}$, fistulados no rúmen e no abomaso, mantidos em regime de confinamento.
Os tratamentos foram constituídos de cana-deaçúcar (Saccharum ssp, L.) suplementada com duas fontes nitrogenadas - uréia e cama de frango (em substituição parcial à uréia), com ou sem adição de Sacharomyces cerevisiae.

A mistura concentrada foi composta de uréia, farelo de algodão, fosfato bicálcico, calcário e sal. As rações foram balanceadas conforme as exigências estabelecidas pelo NRC (1989), para serem similares aos conteúdos proteícos com aproximadamente $12 \%$ em proteína bruta, sendo $50 \%$ dos compostos nitrogenados na forma de $\mathrm{N}$ verdadeiro e $50 \%$ do $\mathrm{N}$ na forma de NNP.

A especificação da composição bromatológica da cultura de levedura utilizada, (YEA-SACC ${ }^{1026}$ ), foi de 89,2\% MS; 33,7\% PB; 6,7\% EE; 15,6\% FDA; 9,4\% MM; 0,26\% Ca; 1,16\% P; 0,63\% S; 0,49\% Mg; 0,18\% Na; 436 ppm Fe; 46 ppm Mn; 19 ppm Cu; 700 ppm Zn; com $10^{6} \mathrm{UFC} / \mathrm{g}$ (Universidade Formadora de Colonia) de MS. A levedura Sacharomyces cerevisiae é produzida a partir da fermentação de um meio contendo milho amarelo, malte e melaço de cana. Posteriormente, as células leveduriformes são secas juntamente com o meio de fermentação e peletizadas a $70^{\circ} \mathrm{C}$.

As porcentagens dos ingredientes utilizados para formulação das rações e as respectivas composições químicas dos alimentos e das rações experimentais estão nas Tabela 1 e 2.

Odelineamento experimental utilizado foi quadrado latino $4 \times 4$ em esquema fatorial $(2 \times 2)$, no qual os fatores foram as duas fontes nitrogenadas e os dois níveis de suplementação com Sacharomyces cerevisiae.

Os fluxos de matéria seca abomasal e fecal foram estimados utilizando-se o teor de FDN indigestível in situ, nas amostras dos alimentos, no abomaso, nas fezes e sobras. As amostras foram incubadas no rúmen em saco de náilon por 144 horas, segundo a metodologia descrita por COCHRAN et al. (1986). Os teores de fibra em detergente neutro na matéria seca dos alimentos e na matéria seca abomasal e fecal foram determinados de acordo com os procedimentos descritos por VAN SOEST et al. (1991). Os teores de nutrientes digestíveis totais (NDT) e energia metabolizável das rações foram calculados conforme recomendações de SNIFFEN et al. (1992).

A cada período experimental, foram utilizados 10 dias de adaptação à dieta; quatro dias para as coletas de fezes e digesta de abomaso realizadas a intervalos de oito horas, com espaço de seis horas entre dias, de modo que, no final de quatro dias, fossem obtidas 12 
Tabela 1 - Composição bromatológica em matéria seca (MS), proteína bruta (PB), matéria orgânica (MO), matéria mineral $(\mathrm{MM})$, extrato etéreo (EE), carboidratos totais (CT), fibra em detergente neutro corrigida para cinza e proteína $\left(F D N_{\mathrm{cp}}\right)$ e carboidratos não-estruturais (CNE) dos ingredientes e dos concentrados das rações

Table 1 - Chemical composition of dry matter (DM), crude protein (CP), organic matter (OM), ashes (A), ether extract (EE), total carbohidrates (TC), neutral detergent fiber (NDF) and non structural carbohydrates (NSC) of the ingredients and of the concentrate of the diets

\begin{tabular}{|c|c|c|c|c|c|c|c|c|}
\hline \multirow[t]{2}{*}{ Item } & \multicolumn{6}{|c|}{$\begin{array}{c}\text { Composição bromatológica }(\% \mathrm{MS})^{2} \\
\text { Chemical composition }(\% D M)\end{array}$} & \multirow[b]{2}{*}{$\mathrm{FDN}^{1}$} & \multirow[b]{2}{*}{$\mathrm{CNE}$} \\
\hline & MS & PB & $\mathrm{MO}$ & MM & $\mathrm{EE}$ & $\mathrm{CT}$ & & \\
\hline $\begin{array}{l}\text { Cana-de-açúcar } \\
\text { Sugar cane }\end{array}$ & 27,80 & 2,5 & 97,06 & 2,94 & 0,74 & 93,81 & 57,83 & 35,99 \\
\hline $\begin{array}{l}\text { Cama de frango } \\
\text { Broiler litter }\end{array}$ & 81,29 & 19,60 & 83,03 & 16,97 & 0,45 & 62,98 & 43,47 & 19,51 \\
\hline $\begin{array}{l}\text { Concentrado } 1 \\
\text { Concentrate } 1\end{array}$ & 84,67 & 52,0 & 79,77 & 11,2 & 1,44 & 35,36 & 15,22 & 20,14 \\
\hline $\begin{array}{l}\text { Concentrado } 2 \\
\text { Concentrate } 2\end{array}$ & 86,49 & 51,66 & 77,80 & 10,8 & 1,40 & 36,14 & 14,85 & 21,29 \\
\hline
\end{tabular}

MS, PB, MO, MM, EE, CT, FDN e CNE (DM, CP, OM, A, EE, TC, NDF and NSC).

1 FDN corrigida para cinzas e proteína (NDF corrected for ash and protein).

amostras de digestas de abomaso e fezes por animal, conforme metodologia descrita por CALSAMIGLIA et al. (1995); um dia para a coleta de urina; e um dia de coleta de líquido ruminal para determinação do $\mathrm{pH}$ e das concentrações de $\mathrm{N}-\mathrm{NH}_{3}$.

A ração total foi fornecida à vontade, uma vez ao dia, às $8 \mathrm{~h}$, sendo que as sobras foram previamente pesadas e amostradas para determinação do consumo diário.

A quantidade de ração fornecida foi calculada de modo a permitir sobras de aproximadamente $10 \%$ do total fornecido. Foram realizadas amostras compostas da cana-de-açúcar, da cama de frango e dos concentrados fornecidos e das sobras por animal em cada período. As amostras foram armazenadas a $-5^{\circ} \mathrm{Ce}$, posteriormente, pré-secas em estufa ventilada a $55^{\circ} \mathrm{C}$ por 72 horas, moídas em moinhos com peneira de $1 \mathrm{~mm}$.

Posteriormente, foi elaborada uma amostra composta para cada período, por animal, com base no peso seco. As amostras compostas foram devidamente acondicionadas em recipientes de vidro e, posteriormente, submetidas às análises laboratoriais.

Os teores de matéria seca (MS), matéria orgânica (MO), proteína bruta (PB), matéria mineral (MM) e extrato etéreo (EE) foram determinados seguindo os procedimentos padrões (ASSOCIATION OF OFFICIAL ANALYTICAL CHEMISTS - AOAC, 1990) e os de fibra em detergente neutro (FDN), conforme (VAN SOEST et al., 1991).

As amostras de urina, foram obtidas de coletas ao longo de 24 horas, armazenadas em recepientes plásticos contendo $200 \mathrm{~mL}$ de solução de ácido sulfú- rico $\left(\mathrm{H}_{2} \mathrm{SO}_{4}\right)$ a $10 \%$. Após a coleta, os recipientes contendo urina foram devidamente pesados, para determinação do volume total produzido e homogenizados. Em seguida, foram retiradas alíquotas de aproximadamente $100 \mathrm{~mL}$, devidamente identificadas e armazenadas a $-5^{\circ} \mathrm{C}$ para posterior quantificação de compostos nitrogenados.

As coletas de líquido ruminal, para a determinação do $\mathrm{pH}$ e das concentrações de $\mathrm{N}-\mathrm{NH}_{3}$ foram realizadas imediatamente antes do fornecimento da alimentação e $2,4,6$, e 8 horas após. Foram coletados, por meio da fístula ruminal, aproximadamente, $50 \mathrm{~mL}$ de líquido, procedendo-se à imediata determinação do $\mathrm{pH}$, em potenciometro digital. Após a leitura, adicionou-se, a cada amostra, $1 \mathrm{~mL}$ de solução de $\mathrm{H}_{2} \mathrm{SO}_{4} 1: 1$, para aramzenamento a $-5^{\circ} \mathrm{C}$, determinação posterior das concentrações de $\mathrm{N}_{-} \mathrm{NH}_{3}$. As concentrações de N$\mathrm{NH}_{3}$ nas amostras do líquido ruminal filtrado e nos fluidos de abomaso foram determinadas mediante destilação com hidróxido de potássio $2 \mathrm{~N}$, conforme técnica de Fenner(1965), adaptada por VIEIRA (1980).

Osdados de consumo edigestibilidade foram avaliados por meio de análise de variância, utilizando-se o programa SAEG - Sistema de Análises Estatísticas e Genéticas (UNIVERSIDADEFEDERALDE VIÇOSA-UFV, 1995).

As concentrações de amônia ruminal $\left(\mathrm{N}-\mathrm{NH}_{3}\right)$ e $\mathrm{pH}$ foram analizadas em delineamento inteiramente casualizado, em esquema de parcelas subdivididas, tendo nas parcelas um esquema fatorial $2 \times 2$ (duas fontes nitrogenadas com e sem levedura) e nas subparcelas os tempos de amostragens $(2,4,6,8$ horas após a alimentação) com quatro repetições. 
Rev. bras. zootec.

Tabela 2 - Porcentagem dos ingredientes (\%MS) e composição bromatológica em matéria seca (MS), matéria orgânica (MO), proteína bruta (PB), NNP (nitrogênio não-protéico), extrato étereo (EE), matéria mineral (MM), carboidratos totais (CT), fibra em detergente neutro corrigida para cinzas e proteina $\left(\mathrm{FDN}_{\mathrm{cp}}\right)$, carboidratos não-estruturais $(\mathrm{CNE})$ e concentrações em nutrientes digestíveis totais (NDT) e energia metabolizável (EM) das rações

Table 2 - Percentage of the ingredients (\%DM) and chemical compositions of dry matter (DM), organic matter (OM), crude protein (CP), NPN ( Non protein nitrogen), ether extract (EE), ashes (A), total carbohydrates (TC), neutral detergent fiber corrected for ashes and protein $\left(N D F_{c p}\right)$, non structural carbohydrates (NSC) and total digestible nutrients concentations (TDN) and metabolizable energy of the diets

\begin{tabular}{|c|c|c|c|c|}
\hline \multirow[t]{2}{*}{ Item } & \multicolumn{4}{|c|}{$\begin{array}{l}\text { Tratamento } \\
\text { Treatement }\end{array}$} \\
\hline & 1 & $2^{1}$ & 3 & $4^{1}$ \\
\hline \multicolumn{5}{|l|}{$\begin{array}{l}\text { Porcentagem do ingrediente } \\
\text { Percentage of the ingredient }\end{array}$} \\
\hline $\begin{array}{l}\text { Cana-de-açúcar } \\
\text { Sugar cane }\end{array}$ & 82,53 & 82,53 & 60,14 & 60,14 \\
\hline Cama de frango & - & - & 28,74 & 28,74 \\
\hline $\begin{array}{l}\text { Broiler litter } \\
\text { Farelo de algodão } \\
\text { Cottonseed meal }\end{array}$ & 14,68 & 14,68 & 9,11 & 9,11 \\
\hline $\begin{array}{l}\text { Uréia/Sulfato de amônia (9:1) } \\
\text { Urea/Ammonia sulfate }(9: 1)\end{array}$ & 1,62 & 1,62 & 0,91 & 0,91 \\
\hline $\begin{array}{l}\text { Fosfato bicálcico } \\
\text { Dicalcium phosfate }\end{array}$ & 0,42 & 0,42 & 0,37 & 0,37 \\
\hline $\begin{array}{l}\text { Calcário } \\
\text { Limestone }\end{array}$ & 0,56 & 0,56 & 0,53 & 0,53 \\
\hline Sal & 0,19 & 0,19 & 0,19 & 0,19 \\
\hline $\begin{array}{l}\text { Salt } \\
\text { Composição bromatológica }{ }^{5}\end{array}$ & & & & \\
\hline $\begin{array}{l}\text { Chemical composition } \\
\text { MS\% }\end{array}$ & 3773 & 3773 & 4969 & 4969 \\
\hline $\mathrm{MO}^{2}$ & 95,62 & 95,62 & 92,16 & 92,16 \\
\hline $\mathrm{PB}^{2}$ & 11,15 & 11,15 & 12,87 & 12,87 \\
\hline $\mathrm{NNP}^{3}$ & 24,18 & 24,18 & 21,81 & 21,81 \\
\hline $\mathrm{EE}^{2}$ & 0,85 & 0,85 & 0,73 & 0,73 \\
\hline $\mathrm{MM}^{2}$ & 4,38 & 4,38 & 7,84 & 7,84 \\
\hline $\mathrm{CT}^{2}$ & 83,62 & 83,62 & 78,56 & 78,56 \\
\hline $\mathrm{FDN}_{\mathrm{CP}}{ }^{2}$ & 50,38 & 50,38 & 48,92 & 48,92 \\
\hline $\mathrm{CNE}^{2 \mathrm{~T}}$ & 33,24 & 33,24 & 29,64 & 29,64 \\
\hline $\mathrm{NDT}^{2}$ & 54,46 & 52,42 & 44,47 & 47,56 \\
\hline $\mathrm{EM}^{4}$ & 1,97 & 1,89 & 1,62 & $1,72^{1}$ \\
\hline
\end{tabular}

$110 \mathrm{~g}$ de Sacharomyces cerevisiae/animal/dia.

2 Porcentagem da MS (DM \%).

3 Porcentagem da PB (CP\%).

${ }^{4} \mathrm{kcal} / \mathrm{g} \mathrm{MS}$.

${ }^{5} \mathrm{MS}, \mathrm{PB}, \mathrm{NNP}, \mathrm{MO}, \mathrm{MM}, \mathrm{EE}, \mathrm{CT}, \mathrm{FDN}_{\mathrm{cp}}$, CNE, NDT e EM (DM, CP,NPN, OM, A, EE,TC, NDF $\left.{ }_{a p,} N S C, T D N, M E\right)$.

\section{Resultados e Discussão}

Os consumos médios diários de MS, MO, PB, EE, CT, FDN, CNE e NDT, expressos nas diversas formas, com respectivos níveis de significância e coeficientes de variação estão demonstrados na Tabela 3.

Não foi detectado efeito do uso de Sacharomyces cerevisiae, bem como sua interação com as fontes de nitrogênio sobre as variáveis estudadas. A suplementação da cana-de-açúcar com fontes de nitrogênio não alterou os consumos de MS, MO, EE, CT, CNE e NDT.
A substituição parcial da uréia pela cama de frango promoveu maiores consumos de $\mathrm{PB}$, quando expressos em kg/dia $(\mathrm{P}<0,05)$, provavelmente, devido aos maiores teores de $\mathrm{PB}$ verificados nas respectivas dietas (Tabela 3 ).

$\mathrm{O}$ consumo de FDN foi maior para as rações contendo cama de frango $(\mathrm{P}<0,05)$. Apesar de as porcentagens de FDN das dietas terem sido próximas, as dietas constituídas de cama de frango apresentaram 11,96 unidades percentuais de MS (Tabela 2) a mais em relação às dietas com uréia, o que provavelmente, explica a maior ingestão desse nutriente. 
Tabela 3 - Consumos médios de matéria seca (MS), matéria orgânica (MO), proteína bruta (PB), extrato etéreo (EE), carboidratos totais $(\mathrm{CT})$, fibra em detergente neutro corrigida para cinzas e proteína (FDN $\mathrm{cp})$, carboidratos nãoestruturais (CNE) e nutrientes digestíveis totais (NDT) das dietas

Table 3 - Mean intakes of dry matter (DM), organic matter (OM), crude protein (CP), ether extract (EE), total carbohydrates (TC), neutral detergent fiber (NDF), non structural carbohydrates (NSC) and total digestible nutrients (TDN) of diets

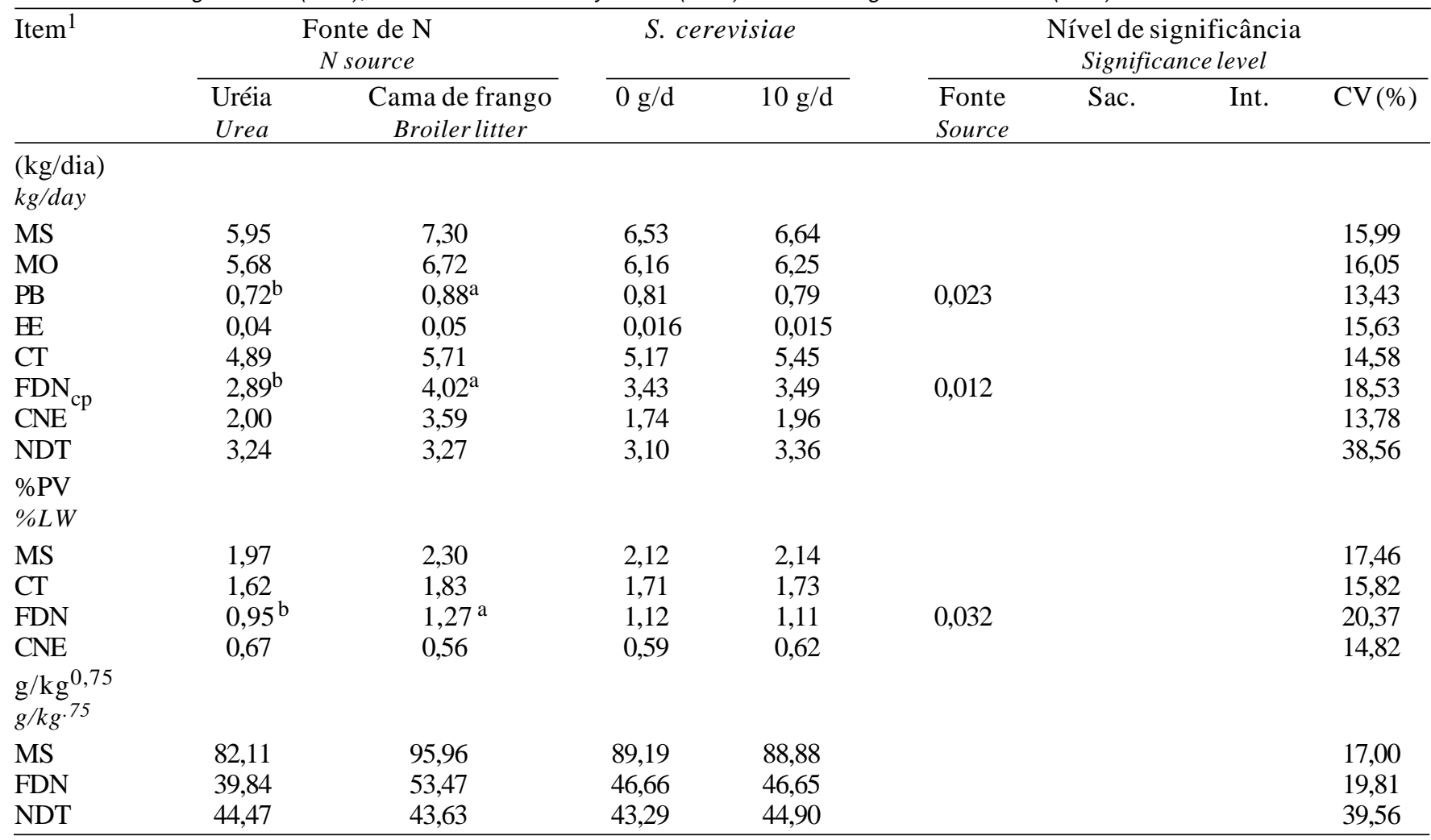

MS, MO, PB, EE, CT, FDN ${ }_{\text {Cp }}$, CNE e NDT (DM, OM, CP, EE,TC, NDF, NSC and TDN). Médias seguidas de letras diferentes são diferentes $(P<0,05)$ pelo teste de $F$. Means followed by different letters are different $(P<.05)$ by $F$ test.

Pode-se inferir que, em virtude de grande proporção de cana-de-açúcar nas rações e da pior qualidade de fibra desse alimento, os animais submetidos a estas dietas raramente ingerem energia suficiente para atender às suas produções potenciais, com exceção das dietas formuladas com níveis mais elevados de concentrado.

Os coeficientes de digestibilidades ruminais (CDR), intestinais (CDI) e totais (CDT) para MS, $\mathrm{MO}, \mathrm{PB}, \mathrm{EE}, \mathrm{CT}, \mathrm{FDN}_{\mathrm{cp}}$ e CNE e os respectivos coeficientes de variação estão apresentados na Tabela 4. A inclusão de Sacharomyces cerevisiae, bem como sua interação com as fontes de nitrogênio, não influenciou $(\mathrm{P}>0,05)$ os coeficientes de digestibilidade dos nutrientes estudados. Resultados semelhantes ao deste trabalho foram obtidos por DOREAU e JOUANY (1998), os quais observaram que a utilização de Sacharomyces cerevisiae não influenciou a digestibilidade dos nutrientes, o que também foi observado previamente por CARRO et al. (1992) e HUHTANEN (1991).
Detectaram-se valores negativos para os coeficientes de digestibilidade ruminal aparente de PB, para todos os tratamentos, demonstrando que não houve perdas de nitrogênio na forma de amônia, o que, segundo DIAS (1999), pode ser indicativo de deficiência dietética de proteína, ou maior reciclagem endógena. Valor negativo para o coeficiente de digestibilidade aparente para o extrato etéreo no rúmen foi observado para as dietas suplementadas com cama de frango, indicando que pode ter ocorrido síntese de lipídeos microbianos, conforme relataram CARVALHO et al. (1997) e DIAS (1999). As digestibilidades aparentes totais de PB e EE foram maiores para as dietas constituídas de uréia (Tabela 4). O coeficiente de digestibilidade total da proteína para as dietas constituídas de uréia apresentaram valor médio de $61,08 \%$; quando se usa uréia, a digestibilidade da PB é maior, devido ao fato de a principal via de excreção do $\mathrm{N}$ ser na urina, e não nas fezes. Os coeficientes de digestibilidade aparente 
Rev. bras. zootec.

total da PB deste trabalho são inferiores aos obtidos por AROEIRA et al. (1993), que relataram coeficientes de digestibilidade aparente total da ordem de $75 \%$.

A interação entre as fontes de nitrogênio e a utilização de Sacharomyces cerevisiae não foi significativa para qualquer variável estudada. A substituição parcial da uréia pela cama de frango influenciou $(\mathrm{P}<0,01)$ a ingestão de $\mathrm{N} \mathrm{em} \mathrm{kg/dia,} \mathrm{observando-se}$ maior consumo de $\mathrm{N}$ para as dietas constituídas com cama de frango, como observado por MIRANDA (1998), trabalhando com dietas semelhantes em novi- lhas mestiças, como reflexo do maior consumo de MS.

Com relação à excreção de $\mathrm{N}$ fecal expressa em $\mathrm{g} /$ dia e em $\mathrm{g} / \mathrm{kg}^{0,75}$, não foi observada diferença entre as dietas suplementadas com uréia ou cama de frango, bem como pela utilização de Sacharomyces cerevisiae.

A excreção de $\mathrm{N}$ na urina, expressa em g/dia e $\mathrm{g} / \mathrm{kg}^{0,75}$, foi maior $(\mathrm{P}<0,01)$ para as dietas suplementadas com uréia, apresentando valores de $49,80 \mathrm{~g} / \mathrm{dia}$ e $0,70 \mathrm{~g} / \mathrm{kg} \mathrm{PV}^{0,75}$, pois, quando a taxa de degradação da proteína excede a taxa de degradação dos carboidratos, grandes quantidades de $\mathrm{N}$ podem ser

Tabela 4 - Coeficientes de digestibilidade aparente total (CDT), ruminal (CDR) e intestinal (CDI) de matéria seca (MS), matéria orgânica (MO), proteína bruta (PB), extrato etéreo (EE), carboidratos totais (CT), fibra em detergente neutro corrigida para cinzas e proteína $\left(F D N_{c p}\right)$ e carboidratos não-estruturais $(\mathrm{CNE})$ das dietas

Table 4 - Coefficient of total apparent digestibility (CTD), ruminal (CRD) and intestinal (CID) of dry matter (DM), organic matter (OM), crude protein (CP), ether extract (EE), total carbohydrates (TC), neutral detergent fiber (NDF) and non structural carbohydrates (NSC) of diets

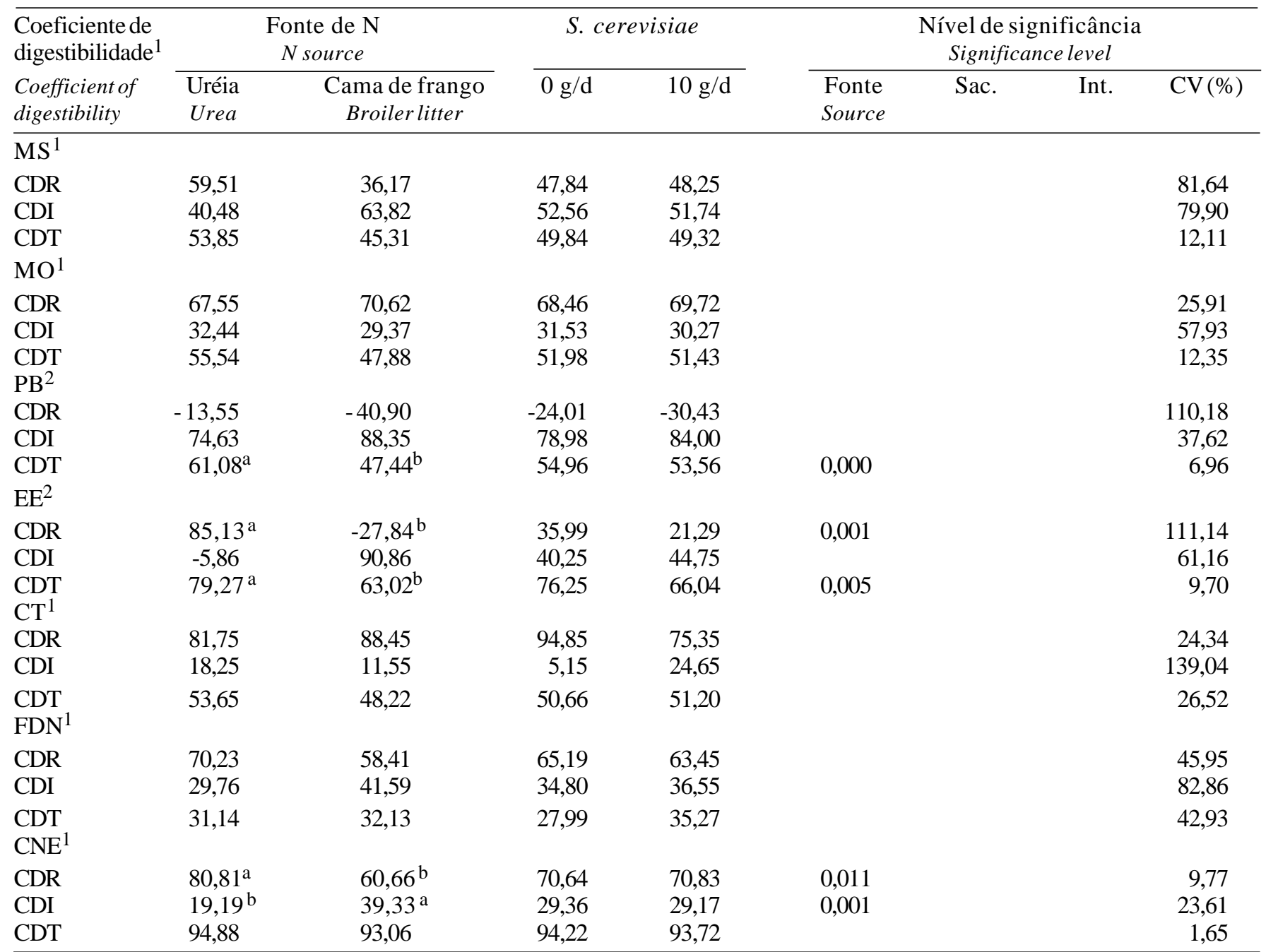

MS, MO, PB, EE, CT, FDN e CNE (DM, OM, CP, EE,TC, NDF and NSC) (and CDT, CDRe CDI [CTD, CRD and CID]).

1 Digestibilidade calculada em função do total digestível.

2 Expressa em função da quantidade que chegou no local.

Médias seguidas de letras diferentes são diferentes $(P<0,05)$ pelo teste de $F$.

1 Digestibility calculated in fuction of the total digestible.

2 Expressed in fucntion of the amount that arrived in the place.

Means followed by different letters are different $(P<.05)$ by $F$ test. 
perdidas na forma de amônia (RUSSELL et al.1992).

Os coeficientes de digestibilidade aparente e os locais de digestão mostrados na Tabela 4, para carboidratos totais e $\mathrm{FDN}_{\mathrm{cp}}$, indicaram que estes não foram influenciados pelas fontes nitrogenadas e pelo uso de Sacharomyces cerevisiae. Foram detectados coeficientes de digestibilidades ruminal de CNE maiores $(\mathrm{P}<0,05)$ para as dietas com cana e uréia em relação às constituídas de cama de frango, em virtude desses tratamentos apresentarem maiores proporções de componentes solúveis em detergente neutro e, conseqüentemente, maior disponibilidade no meio ruminal. Comportamento contrário foi observado para os coeficientes de digestibilidade intestinais.

Na Tabela 5, são demonstrados os valores médios diários de consumo total de compostos nitrogenados ingeridos, excretados nas fezes e na urina, e o balanço de $\mathrm{N}(\mathrm{BN})$.

$\mathrm{O}$ balanço de nitrogênio, independente do modo como foi expresso, não foi influenciado pelas fontes nitrogenadas e nem pela adição de Sacharomyces cerevisiae. É importante ressaltar que não se verificou BN negativo para os tratamentos, o que pode indicar que as exigências protéicas dos animais foram atendi- das, pois os consumos médios de proteína das dietas foram de $0,8 \mathrm{~kg} / \mathrm{dia}$, sendo próximos ao valor médio de $0,77 \mathrm{~kg} /$ dia para ganho de $700 \mathrm{~g} /$ dia (NRC, 1989).

As equações de regressão ajustadas para as leituras de pH no líquido ruminal, em função do tempo, para as quatro rações experimentais, estão expressas na Figura 1. A substituição parcial da uréia pela cama de frango, com ou sem adição de Sacharomyces cerevisiae, não influenciou o $\mathrm{pH}$ ruminal $(\mathrm{P}>0,05)$, semelhante ao observado por DOREAU e JOUANY (1998). Verificou-se redução linear nos valores de pH para as dietas suplementadas com uréia, devido provavelmente à intensificação do processo de fermentação após a alimentação e ao conseqüente aumento nas concentrações de ácidos graxos voláteis. Constatou-se efeito quadrático para o tratamento constituído de uréia com Sacharomyces, apresentando pH mínimo de 5,99 às 8,98 horas após o fornecimento da alimentação. As dietas constituídas de cama de frango e adicionadas de Sacharomyces cerevisiae não proporcionaram variação no $\mathrm{pH}$ ruminal, apresentando valores médios de 6,80 e 6,75, respectivamente. Os valores médios de $\mathrm{pH}$ observados para todas as dietas estiveram dentro da faixa aceitável para máximo

Tabela 5 - Valores médios para compostos nitrogenados ingeridos $(\mathrm{N})$, excretado nas fezes e na urina, e balanço de $\mathrm{N}$ Table 5 - Means values of ingested nitrogenous compounds (IN), fecal and urinary excretion, and $N$ balance

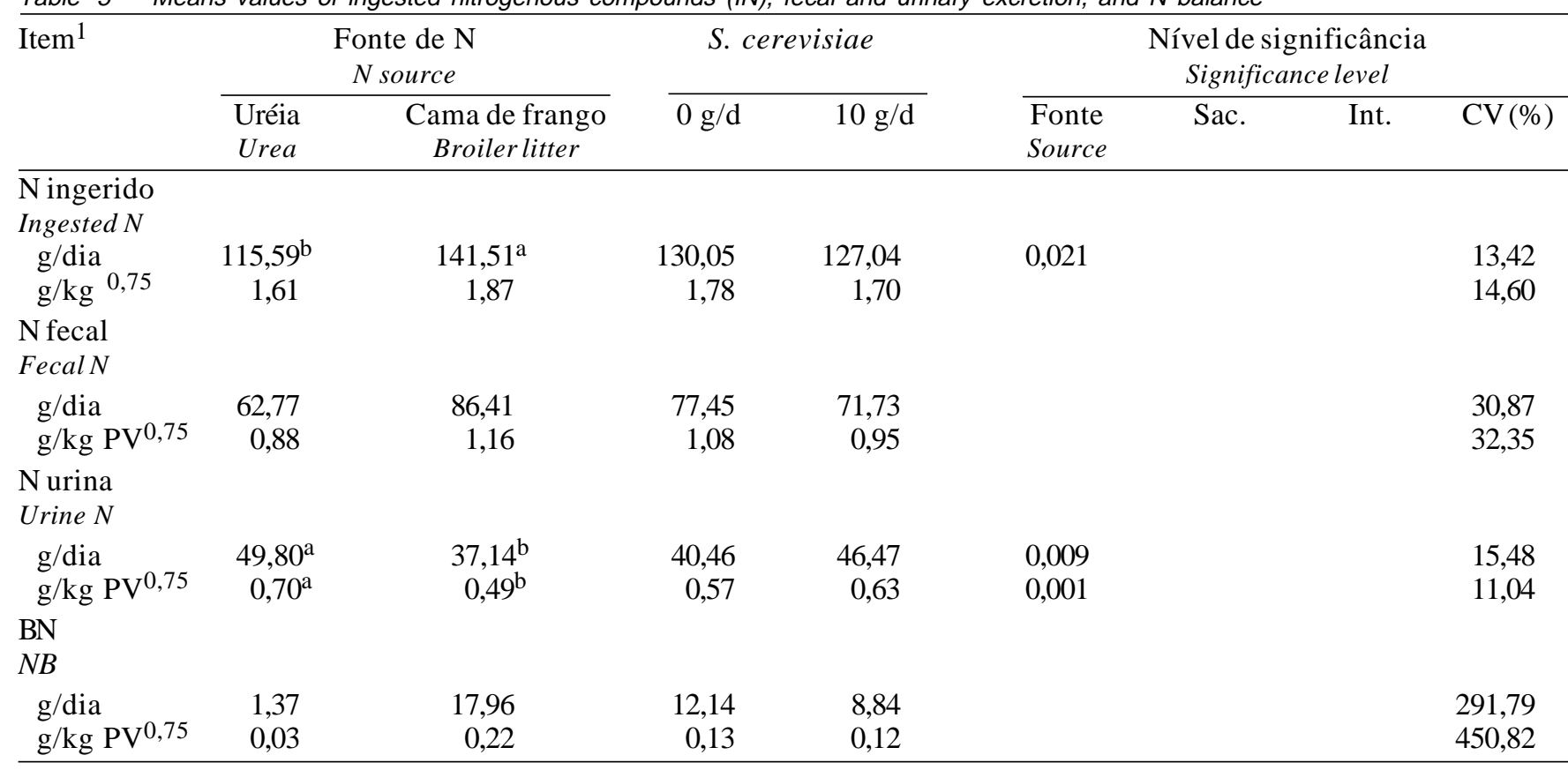

Médias seguidas de letras diferentes são diferentes $(P<0,05)$ pelo teste de $F$.

Means followed by different letters are different $(P<.05)$ by $F$ test. 


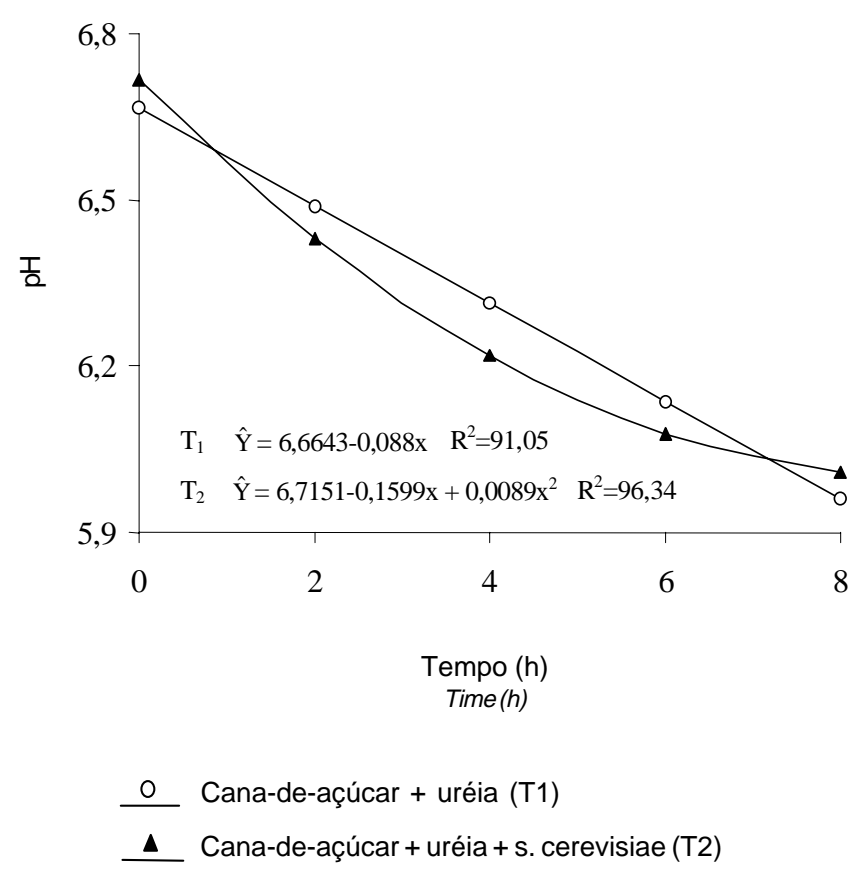

Figura 1 - Estimativas de pH do líquido ruminal, em função dos tempos de coleta, para as dietas.

Figure 1 - Estimates of $\mathrm{pH}$ of the ruminal fluid, in function of collection time, for the diets.

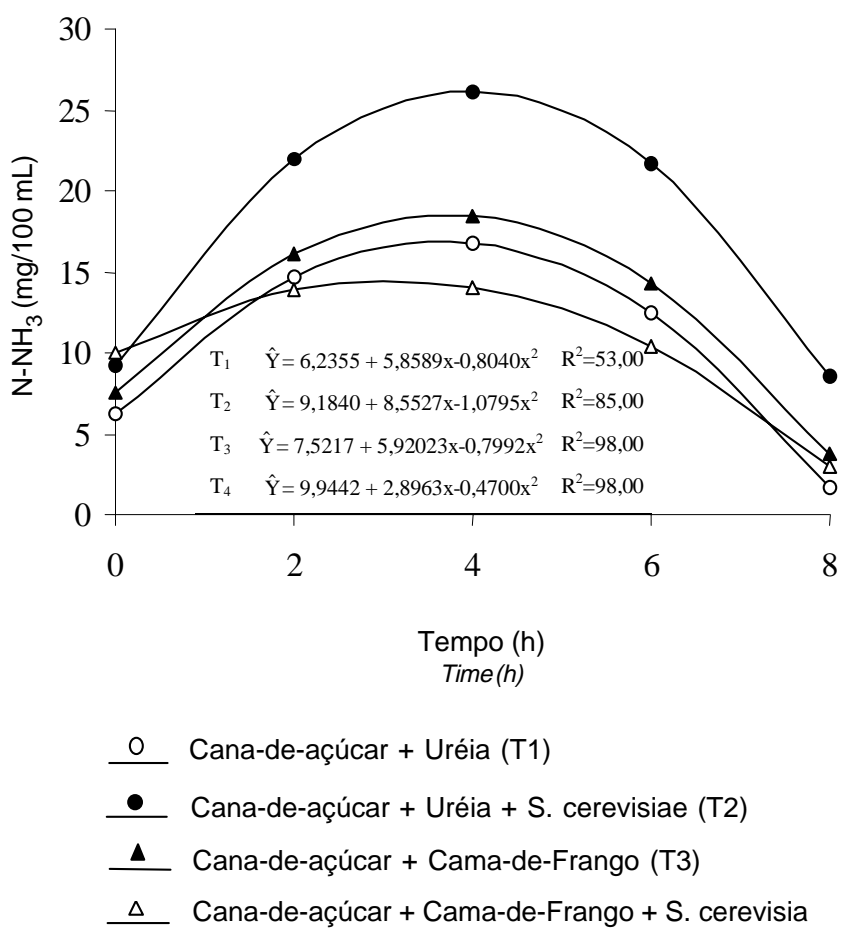

Figura 2 - Estimativas das concentrações de nitrogênio amoniacal ruminal $\left(\mathrm{N}-\mathrm{NH}_{3}\right)$, em função do tempo de coleta, para as dietas.

Figures 2 - Estimates of the concentrations of ruminal ammonia nitrogen $\left(\mathrm{N}-\mathrm{NH}_{3}\right)$, in function of the collection time, for the diets.

tivamente. Este comportamento está de acordo com as observações de HENNESSY et al. (1995), que registraram em novilhos maior concentração de amônia três horas após a alimentação. A concentraçãos média de nitrogênio amoniacal em todas as dietas estiveram acima do mínimo requerido, para máximo crescimento microbiano e máxima taxa de digestão, que, segundo SATTER e SLYTER (1974), é de $5 \mathrm{mg} / 100 \mathrm{~mL}$.

\section{Conclusões}

A utilização de Sacharomyces cerevisiae não influenciou os consumos e os coeficientes de digestibilidade de MS, MO, PB EE, CT, FDN ${ }_{\mathrm{cp}}$, CNE.

A substituição parcial da uréia pela cama de frango, como fonte de NNP, não influenciou as digestões ruminais e intestinais da MS, MO, PB, CT, $\mathrm{FDN}_{\mathrm{cp}}$, porém diminuiu a digestibilidade ruminal do EE e CNE. 


\section{Referências Bibliográficas}

AROEIRA, L.J.M., SILVEIRA, M.I., LIZIERE, R.S. et al. 1993. Digestibilidade, balanço de nitrogênio e concentração de amônia no rúmen de novilhos mestiços alimentados com cana-de-açúcar-uréia mais farelos de arroz ou de algodão. R. Soc. Bras. Zootec., 22(6):893-901.

ASSOCIATION OF OFFICIAL ANALYTICAL CHEMISTS AOAC. 1990. Official methods of analysis. v. 1, 15.ed., Virginia: Arlington. 1117p.

CALSAMIGLIA, S., CAJA, G., STERN, M. D. et al. 1995. Effects of ruminal versus duodenal dosing of fish meal on ruminal fermentation and milk composition. J. Dairy Sci., 78(9):1999-2007.

CARRO, M.D., LEBZIEN, P., ROHR, K. 1992. Effects of yeast culture on rumen fermentation, digestibility and duodenal flow in dairy cows fed a silage based diet. Livest. Prod. Sci., 32:219-229.

CARVALHO, A.U., VALADARES FILHO, S.C., COELHO DA SILVA, J.F. et al. 1997. Níveis de concentrados em dietas de zebuínos. 2. Coeficientes e digestibilidades aparentes parciais. R. Bras. Zootec., 26(5):996-1006.

CECAVA, M.J., MERCHEN, N.R., GAY, L.C. et al. 1990. Composition of ruminal bacteria harvested from steers as influenced by dietary energy level, feeding frequency and isolation techniques. J. Dairy Sci., 73:2480-2488.

COCHRAN, R.C., ADAMS, D.C., WALLACE, J.D. et al. 1986. Predicting digestibility diets with internal markers: evaluation of four potential markers. J. Anim. Sci., 63:1476-1483.

DIAS, H.L.C. Consumo, digestibilidade e eficiência microbiana em novilhos $F_{1}$ Limousin $x$ Nelore alimentados com dietas contendo cinco níveis de concentrado. Viçosa MG: UFV, 1999. 76p. Dissertação (Mestrado em Zootecnia) - Universidade Federal de Viçosa, 1999.

DOREAU, M., JOUANY, J.P. 1998. Effect of a Sacharomyces cerevisiae culture on nutrient digestion in lactating dairy cows. J. Dairy Sci., 81(12):3214-3221.

HENNESSY, D.W., KOHUN, P.J., WILLIAMSON, P.J. et al. 1995. The effect of nitrogen and protein supplementation on feed intake, growth and digestive function of steers with different Bos indicus, Bos taurus genotyps when fed a low quality grass hay. Aust. J. Agric. Sci., 46(6):1122-11-36.

HOOVER, W.H., STOKES, S.R. 1991. Balancing carbohydrates and proteins for optimum rumen microbial yield. J. Dairy Sci., 74:3630-3644.

HUHTANEN, P. 1991. Effects of yeast culture supplement on digestion of nutrients and rumen fermentation in cattle fed on grass silage barley diet. J. Agric. Sci., 71:443-453.

LENG, R.A. 1993. Quantitative ruminant nutrition - a green science. Aust. Agric. Res., 44:363-380.

MARTIN, S.A., NISBET, D.J. 1992. Effect of direct-fed microbials on rumen microbial fermentation. J. Dairy Sci., 75:1736-1744.

MERCHEN, N.R., ELIZALDE, J.C., DRACHLEY, J.K. 1997. Current perspective on assessing site of digestion in ruminants. J. Anim. Sci., 75(8):2223-2234.

MERTENS, D. R. Análise da fibra e sua utilização na avaliação e formulação de rações. In: SIMPÓSIO INTERNACIONAL DE RUMINANTES, REUNIÃO ANUAL DA SOCIEDADE BRASILEIRA DE ZOOTECNIA, 29, Lavras, 1992. Anais... Lavras: SBZ, 1992. p.188-219.

MERTENS, D.R. 1993. Rate and extent of digestion. Chap. II. In: FORBES, J.M., FRANCE, J. (Eds.) Quantitative aspects of ruminant digestion and metabolism. Cambridge: Commonwealth Agricultural Bureaux, Cambridge University Press. p.13-51.
MERTENS, D.R. 1994. Regulation of forage intake. In: FAHEY, J.F.G.C. (Ed). Forage quality evaluation and utilization. Madison: American Society of Agronomy, Inc., Crop Science Society of America, Inc., Soil Science of America. p.450-493.

MIRANDA, L.F. Desempenho, desenvolvimento ponderal e comportamento ingestivo de novilhas leiteiras alimentadas com dietas à base de cana-de-açúcar. Viçosa: UFV, 1998. 55p. Dissertação (Mestrado em Zootecnia) - Universidade Federal de Viçosa, 1998.

MPOFU, I.D.T., NDLOVU, L.R. 1994. The potential of yeast and natural fungi for enhancing fiber digestibility of forages and roughage. Anim. Feed Sci. Techn., 48:39-47.

NATIONAL RESEARCH COUNCIL - NRC. 1989. Nutrient requirements of dairy cattle. 6.ed. Washington, D.C. 157p.

NEWBOLD, C.J., WALLACE, R.J., CHEN, X.B. et al. 1995. Different strains of Saccharomyces cerevisiae differ in their effects on ruminal bacterial numbers in vitro and in sheep. J. Anim. Sci., 73(6):1811-1818.

NOLAN, J.V. 1993. Nitrogen metabolism by ruminal microorganisms: current understanding and future perspectives. Aust. J. Agric. Res., 47(2):227-246.

ORPIN,C.G., JOBLIN, K.N. 1988. The rumen anaerobic fungi. In: HOBSON, P.N. The rumen microbial ecosystem. London: Elsevier Applied Science. p.129-150.

ORSKOV, E.R., McDONALD, I. 1979. The estimation of protein degradability in the rumen from incubation measurements weighted according to rate of passage. J. Agric. Sci., 92(2):499-503.

RUSSELL, J.B., O'CONNOR, J.D., FOX, D.G. et al. 1992. A net carbohydrate and protein system for evaluating cattle diets. I. Ruminal fermentation. J. Anim. Sci., 70(11):3351-3561.

SATTER, L.D., SLYTER, L.L. 1974. Effect of ammonia concentration on rumen microbial protein production in vitro. Brit. J. Nut., 32(2):199-208,.

THIAGO, L.R.L.S., GILL, M. 1990.Consumo voluntário: fatores relacionados com a degradação e passagem da forragem pelo rúmen. Campo Grande: EMBRAPA-CNPGC. 65p.

UNIVERSIDADE FEDERAL DE VIÇOSA. 1995. Sistema de análises estatísticas e genética-SAEG. Viçosa, MG: UFV. (Apostila).

VAN MILGEN, J., MURPHY, M.R., BERGER, L.L. 1991. A compartimental model to analyze ruminal digestion. J. Dairy Sci., 74(9):2515-2529.

VAN SOEST, P.J. 1994. Nutritional ecology of the ruminant. 2. ed., London, Comstock Publishing Associates, USA. 476p.

VAN SOEST, P.J., ROBERTSON, J.B., LEWIS, B.A. 1991. Methods for dietary fiber, neutral detergent fiber, and nonstarch polysaccharides in relation to animal nutrition. J. Dairy Sci., 74(10):3583-3597.

VIEIRA, F. Efeito do formaldeído na proteção de proteínas e lipídios em rações para ruminantes. Viçosa: UFV, 1980. 98p. Tese (Doutorado em Zootecnia) - Universidade Federal de Viçosa, 1980.

VIEIRA, R.A.M., PEREIRA, J.C., MALAFAIA, P.A.M. et al. 1997a. Application of non-linear models in the description of in situ degradation profiles of the elephant-grass (Pennisetum purpureum Schum., Mineiro variety). Anim. Feed Sci. Techn., 66:197-210.

YOON, I.K., STERN, M.D. 1995. Influence of direct-fed microbials on ruminant microbial fermentation and performance of ruminants. A review. J. Anim. Sci., 8:533-555.

Recebido em: 08/02/00 Aceito em: 06/12/00 